\title{
Sixteen years later and the debate for transcatheter aortic valve replacement or surgical aortic valve replacement remains controversial
}

\author{
Saina Attaran, MD, and Vinod H. Thourani, MD
}

\author{
From the Department of Cardiac Surgery, MedStar Heart and Vascular Institute, Georgetown University, Wash- \\ ington, DC. \\ Disclosures: Authors have nothing to disclose with regard to commercial support. \\ Received for publication Feb 25, 2018; accepted for publication Feb 28, 2018. \\ Address for reprints: Vinod H. Thourani, MD, Department of Cardiac Surgery, Medstar Heart and Vascular Insti- \\ tute, 110 Irving St, Room 6D15G, Washington, DC 20010 (E-mail: vinod.h.thourani@ medstar.net). \\ J Thorac Cardiovasc Surg 2018;156:1015-6 \\ $0022-5223 / \$ 36.00$ \\ Copyright (C) 2018 by The American Association for Thoracic Surgery \\ https://doi.org/10.1016/j.jtcvs.2018.02.080
}

Catheter-based approach of the treatment of aortic stenosis was initiated with balloon aortic valvuloplasty in the 1980s. ${ }^{1}$ Approximately 20 years later, the first transcatheter aortic valve implantation in a human was performed in France by Alain Cribier in 2002. ${ }^{2}$ For almost another 16 years, numerous randomized and registry investigations have been conducted with the hopes of optimizing the appropriate treatment strategy for the management of severe aortic valve stenosis.

In the current study by Armoiry and colleagues, ${ }^{3}$ the authors have eloquently performed a propensity-matched comparison between high-risk patients undergoing transcatheter aortic valve replacement (TAVR) or surgical aortic valve replacement (SAVR) in France during 2010. They have reported follow-up data of up to 5 years based on a very strong French database or Medical Information System, decreasing the chances of patients missing to followup. Another important end point included the economic evaluation and assessment between the 2 groups, a critical factor that is not available in most previously published series. They have reported a similar outcome between SAVR and TAVR in regard to mortality, reoperation, myocardial infarction, and stroke at 1 year. This is comparable to outcomes from the randomized controlled trials with the balloon- and self-expandable trials in the United States. ${ }^{4,5}$ However, from the 1- to 5-year follow-up, Armoiry and colleagues ${ }^{3}$ note a trend toward increasing the risk of mortality, reoperation, and stroke in the TAVR group compared with SAVR. This is in contrast to the 5-year follow-up in the high-risk trial with the SAPIEN valve, in which there were similar rates of morbidity and mortality between SAVR and TAVR. ${ }^{6}$

It is important to note some limitations of the current study, which is based on a national administrative database. Because the authors did not provide any of the commonly reported risk scores (the Society of Thoracic Surgeons or

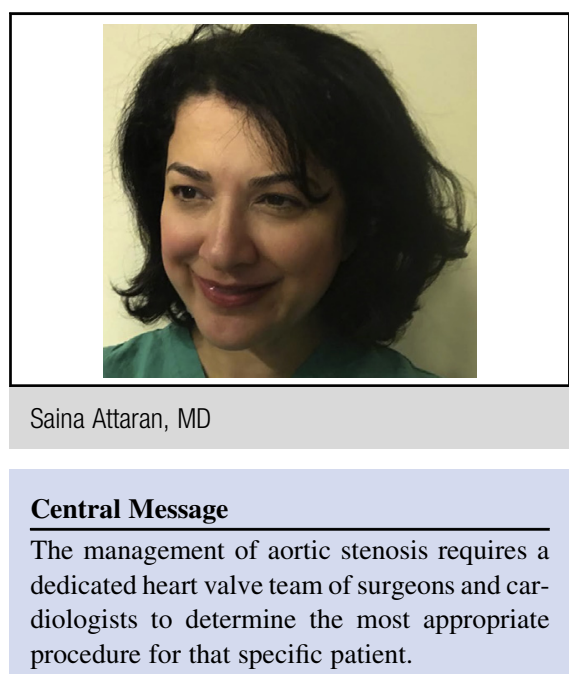

See Article page 1017.

European System for Cardiac Operative Risk Evaluation II), it remains questionable which patient population the authors are actually representing. Clearly in 2010, if the patients were too high risk for surgery or had extreme frailty, they underwent TAVR and not SAVR. There are also several factors, such as porcelain aorta or dementia, that can increase the possibility of a patient undergoing TAVR who may demonstrate a higher mortality and explain the differences seen at longer-term follow-up. It is difficult to adjust for those variables in this current propensitymatched analysis.

The amount of precise preprocedural and periprocedural granularity is not available in the current administrative database study. For example, in 2010, the only commercial available TAVR device was a first-generation device, of which approximately $45 \%$ of patients generally underwent transapical TAVR. A breakdown of the transfemoral and transapical TAVR would have been extremely helpful, especially because it has been well documented that transapical TAVR has a similar or even worse prognosis when compared with SAVR.

It remains extremely important to report "real-world" data as new technology becomes available worldwide. However, results of administrative database registries without preprocedural or procedural granularity should be interpreted with caution. Long-term follow-up of 
randomized trials remains paramount and should drive guideline modification and clinical practice. Maybe the more controversial topic really lies in the comparison of TAVR or SAVR in low-risk patients, because the 2 randomized low-risk trials have completed enrollment and are poised to be reported in 2019 .

\section{References}

1. Lababidi Z. Aortic balloon valvuloplasty. Am Heart J. 1983;106:751-2.

2. Cribier A, Eltchaninoff H, Bash A, Borenstein N, Tron C, Bauer F, et al Percutaneous transcatheter implantation of an aortic valve prosthesis for calcific aortic stenosis: first human case description. Circulation. 2002;106: 3006-8.

3. Armoiry X, Obadia J-F, Pascal L, Polazzi S, Duclos A. Comparison of transcatheter to surgical aortic valve implantation in high risk patients: a nationwide study in France. J Thorac Cardiovasc Surg. 2018;156:1017-25.e4.

4. Smith CR, Leon MB, Mack MJ, Miller DC, Moses JW, Svensson LG, et al. Transcatheter versus surgical aortic-valve replacement in high-risk patients. $N$ Engl J Med. 2011;364:2187-98.

5. Adams DH, Popma JJ, Reardon MJ. Transcatheter aortic-valve replacement with a self-expanding prosthesis. N Engl J Med. 2014;370:1790-8.

6. Mack MJ, Leon MB, Smith CR, Miller DC, Moses JW, Tuzcu EM, et al. 5-year outcomes of transcatheter aortic valve replacement or surgical aortic valve replacement for high surgical risk patients with aortic stenosis (PARTNER 1): a randomised controlled trial. Lancet. 2015;385:2477-84. 